ISSN 2525-4812 (versão online)

ISSN 2238-7641 (versão impressa)

http://www.revistaterceiramargem.com/

index.php/terceiramargem/index
Recebido em: 31/5/2020

Aprovado para Sober 2020: 23/7/2020

Aceito para RTMA: 28/4/2021

Período de publicação: jan./jul. 2021
Revista Terceira Margem Amazônia

(v. $7 \cdot$ n. $17 \cdot$ Jan./Jun. 2021)

Como citar o artigo:

VIANA, L. F.; HOMMA, A. K. O.; MENEZES, A. J. E. A.; SANTOS, J. C.; NETO FARIAS, J. T.; PENA, H. W. A. Análise econômica do cultivo de açaizeiro irrigado no nordeste paraense. Revista Terceira Margem Amazônia, v. 7, n. 17, p. 155-169, 2021. DOI: http://dx.doi.org/10.36882/2525-4812.2021v7i17.p155-169

\title{
ANÁLISE ECONÔMICA DO CULTIVO DE AÇAIZEIRO (Euterpe oleracea Mart.) IRRIGADO NO NORDESTE PARAENSE
}

\author{
Laisa Faria Viana ${ }^{1}$ \\ Alfredo Kingo Oyama Homma ${ }^{2}$ \\ Antônio José Elias Amorim de Menezes ${ }^{3}$ \\ Jair Carvalho dos Santos ${ }^{4}$ \\ João Tomé Farias Neto ${ }^{5}$ \\ Heriberto Wagner Amanajás Pena ${ }^{6}$
}

Resumo: Análise econômica do cultivo de açaizeiro (Euterpe oleracea Mart.) plantado em terra firme é essencial devido ao alto investimento em irrigação. O objetivo deste trabalho foi avaliar a viabilidade econômica de uma plantação comercial de açaizeiro irrigado por microaspersão. A plantação, de 16 ha e com plantas de 8 anos, estava localizada no município de Igarapé-Açu, estado do Pará, e foi instalada e conduzida segundo práticas regionais de cultivo. Para avaliar a viabilidade, os seguintes índices econômicos foram calculados: valor presente líquido (VPL), valor presente líquido anualizado (VPLa), índice benefício-custo (IBC), retorno adicional sobre investimento (Roia), taxa interna de retorno (TIR) e payback descontado. O fluxo de caixa foi dimensionado para um período de 20 anos, e a taxa mínima de atratividade (TMA) foi fixada em $6,93 \%$. Para a estrutura de produção avaliada na propriedade onde a plantação

\footnotetext{
Meteorologista, mestre em Ciências Ambientais, Universidade do Estado do Pará, Belém, PA.

E-mail: laisaviana@live.com

(D) https://orcid.org/0000-0002-2267-6082

2 Engenheiro-agrônomo, doutor em Economia Aplicada, pesquisador da Embrapa Amazônia Oriental, Belém, PA. E-mail: alfredo.homma@embrapa.br

(D) https://orcid.org/0000-0003-0330-9858

3 Engenheiro-agrônomo, doutor em Sistemas de Produção Agrícola Familiar, pesquisador da Embrapa Amazônia Oriental, Belém, PA.

E-mail: antonio.menezes@embrapa.b

(D) https://orcid.org/0000-0002-3294-5354

4 Engenheiro-agrônomo, doutor em Economia Aplicada, pesquisador da Embrapa Amazônia Oriental, Belém, PA. E-mail: jair.santos@embraba.br (D) https://orcid.org/0000-0003-0052-3998

5 Engenheiro-agrônomo, doutor em Agronomia (Genética e Melhoramento de Plantas), pesquisador da Embrapa Amazônia Oriental, Belém, PA.

E-mail: joao.farias@embrapa.br

(D) https://orcid.org/0000-0002-0404-3556

${ }^{6}$ Economista, doutor em Ciências Agrárias, professor da Universidade do Estado do Pará (UFPA), Belém, PA.

E-mail: heriberto@uepa.br

(D) https://orcid.org/0000-0001-7207-6643
} 
se encontrava, atestou-se elevada viabilidade econômica da atividade, com riqueza acrescentada em VPL da ordem de $\mathrm{R} \$ 983.394,31$ para um horizonte de 20 anos de projeto. A atividade de açaizeiro irrigado por microaspersão é viável, com rendimento líquido de $\mathrm{R} \$ 3.860,40 /$ ha e ganho real de 13,07\%, descontada a taxa real de juros empregada no cálculo do VPL.

Palavras-chave: açaizeiro irrigado, cultivo comercial, viabilidade econômica.

\title{
ECONOMIC ANALYSIS OF AÇAIZEIRO CULTIVATION (Euterpe oleracea Mart.) IRRIGATED IN THE NORTHEAST OF PARA STATE
}

\begin{abstract}
Economic analysis of the cultivation of assai palm tree (Euterpe oleracea Mart.) planted on upland is essential due to the high investment in irrigation. The objective of this work was to evaluate the economic viability of a commercial assai plantation irrigated by micro sprinkler. The 16 ha plantation with eight-year-old plants was located in the municipality of Igarapé-Açu, state of Pará, and was installed and conducted according to regional cultivation practices. To assess feasibility, the following economic ratios were calculated: net present value (NPV), annualized net present value (ANPV), benefit-cost index (BCI), additional return on investment (AROI), internal rate of return (IRR) and discounted payback. The cash flow was designed for a period of 20 years and the minimum attractiveness rate (MAR) was set at $6.93 \%$. For the production structure evaluated on the property where the plantation was located, high economic viability of the activity was attested, with added wealth in NPV of the order of $\mathrm{R} \$ 983,394.31$ for a 20 -year project horizon. The activity of irrigated assai is viable with a yield of R\$ $3,860.40 /$ ha and a real gain of $13.07 \%$, discounting the real interest rate used in the calculation of NPV.
\end{abstract}

Keywords: assai, commercial cultivation, irrigation and economic viability.

\section{Introdução}

A região amazônica destaca-se pelo grande potencial no cultivo de plantas frutíferas nativas, como açaizeiro (Euterpe oleracea Mart.), cupuaçuzeiro (Theobroma grandiflorum, Willd. ex. Spreng., Schum), bacurizeiro (Platonia insignis Mart.), castanheira-do-pará (Bertholletia excelsa H.B.K.), pupunheira (Bactris gasipaes Kunth), entre outros, e por envolver milhares de pequenos produtores, além das agroindústrias de beneficiamento dessas frutas (BARRETO et al., 2012). Dentre essas variedades de frutas, o açaí tem ganhado destaque em âmbito nacional e internacional por ser considerado uma "superfruta", graças a sua composição nutricional rica em lipídeos, fenóis e antocianinas, sendo esta última um poderoso antioxidante que está relacionado à prevenção de doenças cardiovasculares (ROCHA, 2015; YAMAGUCHI et al., 2015).

No estado do Pará, a produção de açaí destaca-se como a segunda maior entre as culturas permanentes. Segundo dados da Pesquisa Agrícola Municipal (PAM) de 2017, publicada pelo Instituto Brasileiro de Geografia e Estatística (IBGE, 2020), de 2015 para 2019, a produção agrícola nacional de açaí aumentou de 1 milhão de toneladas para 1,47 milhão, gerando um valor de produção de R 3,3 bilhões para a economia, consolidando o estado do Pará como o maior produtor do fruto, concentrando $90,79 \%$ da produção nacional.

O reconhecimento do açaizeiro como frutífera de expressão econômica já ultrapassou as fronteiras da Amazônia, ele é comercializado nas grandes capitais do País e no exterior sob as mais diversas formas (FALESI et al., 2010). De toda a produção do açaí, 60\% são consumidos dentro do próprio estado do Pará; 30\%, em outros estados do Brasil; enquanto os 10\% restan- 
tes são exportados para outros países, revelando o mercado interno e o nacional como grandes consumidores do fruto e o mercado externo com enorme potencial de crescimento (PESSOA; TEIXEIRA, 2012; TAVARES; HOMMA, 2015).

O aumento da demanda pelo fruto, ocasionado pelo incremento das exportações, vem sendo utilizado como justificativa para a elevação dos preços ao consumidor local, principalmente na entressafra (janeiro a junho), período em que o preço do fruto chega a quadruplicar (NOGUEIRA et al., 2013). Dados da Associação dos Vendedores Artesanais de Açaí de Belém (Avabel) apontam que uma lata $(14 \mathrm{~kg})$, que custa $\mathrm{R} \$ 40,00$ na época da safra, pode chegar a $\mathrm{R} \$ 140,00$ na entressafra.

O aumento do consumo nacional e internacional tem modificado a forma de produção do açaí, que antes era basicamente extrativa, passando hoje para uma proporção significativa de açaí plantado/manejado e cultivado. Dados mais recentes estimam acima de 85 mil hectares em áreas manejadas e financiadas pelo Banco da Amazônia e Banco do Brasil, gerando aproximadamente 2 mil empregos diretos. Somente na cidade de Belém estima-se o envolvimento de mais de 25 mil pessoas, de forma direta e indireta, no agronegócio do açaí (RODRIGUES et al., 2015a, 2015b).

O manejo de açaizais nas áreas de várzea não tem sido suficiente para atender a demanda do mercado, dando início a uma nova modalidade de produzir açaí por meio do cultivo irrigado em terra firme (NOGUEIRA; SANTANA, 2016). Nesse contexto, a mesorregião Nordeste Paraense tem despertado o interesse dos produtores no plantio de açaizeiros, muitos deles utilizando técnicas produtivas, como manejo, irrigação e adubação, com o objetivo de maximizar a produção do fruto e produzi-lo na entressafra (FARIAS NETO et al., 2011). No município de Óbidos, na mesorregião Baixo Amazonas, fica localizado o maior plantio de açaizeiros, com 1.400 hectares irrigados.

Para muitos produtores o cultivo irrigado em terra firme tem-se mostrado interessante por permitir a mecanização, inclusive na colheita, obtendo-se produtividades bem mais elevadas que os açaizais nativos manejados. Outra vantagem do plantio em terra firme estaria na possibilidade de se efetuar a adubação química, aumentando a produtividade e a reposição de nutrientes no solo, uma vez que essa prática não é possível nas áreas de várzea (HOMMA et al., 2006a).

Apesar da expansão do cultivo de açaizeiro em terra firme, estudos sobre a demanda hídrica da planta ainda são incipientes (HOMMA et al., 2010). Por ser uma palmeira de ocorrência natural em áreas de várzea, o açaizeiro é muito exigente em água. A disponibilidade de água no solo é um fator importante que favorece a sobrevivência da planta sobretudo em regiões com precipitação mensal abaixo de $100 \mathrm{~mm}$ ou onde há ocorrência de veranicos, como é o caso do Nordeste Paraense.

Em cultivos de açaizeiro em terra firme, a irrigação tem fundamental importância na redução da sazonalidade, possibilitando incrementos na produtividade e a obtenção de frutos de melhor qualidade sanitária, viabilizando a produção no período de entressafra e evitando a ociosidade das pessoas envolvidas na exploração e no processamento dos frutos (DIMENSTEIN; FARIAS NETO, 2008). 
Embora o sistema de produção de açaizeiro irrigado venha aumentando no estado nos últimos anos, existem poucas informações disponíveis sobre custo da irrigação, perfil dos irrigantes e qualidade da irrigação (SOUZA et al., 2012). Na agricultura irrigada uma produção eficiente e rentável deve constituir o principal objetivo econômico, sendo importante conhecer o grau de risco envolvido na aquisição de novas tecnologias (BARNERS et al., 2015; SILVA et al., 2016). A irrigação é uma tecnologia que requer alto investimento inicial, em torno de $\mathrm{R} \$ 8$ mil a $\mathrm{R} \$ 10$ mil por hectare, e está associada ao uso intensivo de insumos agrícolas, o que torna importante a análise econômica dos componentes de custo envolvidos no sistema (ALVES JÚNIOR et al., 2015).

Devido à carência de informações sobre a produção de açaizeiro irrigado no estado do Pará, tanto no aspecto do manejo adequado da irrigação quanto em relação ao estudo de viabilidade econômica dessa tecnologia de produção, constatou-se a necessidade de estudos mais aprofundados sobre a possibilidade de inserção dessa tecnologia como alternativa de investimento, assim como elementos sucintos para avaliação das potencialidades da atividade irrigada. Nesse sentido, o estudo tem por objetivo avaliar a viabilidade econômica de um cultivo comercial de açaizeiro irrigado, localizado no Nordeste Paraense.

\section{Material e Métodos}

\section{Fonte de Dados}

O estudo se baseia em uma pesquisa aplicada, quantitativa e exploratória, mas com uso de dados empíricos, uma vez que estes foram coletados com base em informações de um cultivo comercial de 16 ha de açaizeiro irrigado, localizado no município de Igarapé-Açu, mesorregião Nordeste Paraense. A coleta de dados foi realizada por meio de observação direta das atividades desenvolvidas na propriedade e por entrevistas não estruturadas com o proprietário e seus funcionários.

Também foram utilizados documentos do proprietário referentes aos gastos com insumos e as receitas obtidas com a venda do açaí, anotados desde a implantação do empreendimento. Após coletadas, as informações foram observadas, organizadas, interpretadas e analisadas, de modo a proporcionar compreensibilidade dos conteúdos, podendo, assim, alcançar o objetivo do trabalho.

A análise da viabilidade econômica foi feita de acordo com os métodos de avaliação econômica que levam em consideração a variação do capital no tempo: o valor presente líquido (VPL), o valor presente líquido anualizado (VPLa), a taxa interna de retorno (TIR), o índice benefício/ custo (IBC), o retorno adicional sobre o investimento (Roia) e o payback descontado. Para todos os cálculos foi utilizada uma taxa de $6,65 \%$ ao ano, a mesma utilizada pelo FNO (Banco da Amazônia) no enquadramento da atividade. O período de fluxo de caixa do projeto foi de 20 anos.

\section{Valor Presente Líquido (VPL)}

O VPL é definido como a soma algébrica dos valores descontados do fluxo de caixa a ele associado (REZENDE; OLIVEIRA, 2013). Dessa forma, os fluxos de caixa futuros, durante a vida útil do projeto, são descontados para o tempo inicial do projeto a uma taxa de juros que re- 
presenta o mínimo de retorno do capital. O critério de aceitação do projeto baseia-se na premissa de aceitá-lo caso o VPL seja positivo. O VPL foi calculado conforme a seguinte equação:

$V P L=\sum_{j=0}^{n} F C D(1+i)^{-1}+F C o$

em que:

$F C D=$ fluxo de caixa descontado.

$F C o=$ fluxo de caixa inicial.

$I=$ taxa de desconto.

$n=$ duração do projeto, em anos.

\section{Valor Presente Líquido Anualizado (VPLa)}

O VPLa consiste em uma variação do método do VPL. Enquanto o VPL concentra todos os valores do fluxo de caixa na data zero, o VPLa transforma o valor atual do projeto em fluxo de receitas ou custos periódicos e contínuos, equivalentes ao valor atual, durante a vida útil do projeto (SOUZA; CLEMENTE, 2004). Trata-se de uma medida importante, visto que é mais fácil para o produtor/investidor raciocinar em termos de ganho por período do que em termos de ganho acumulado ao longo de diversos períodos. O VPLa do projeto é representado pela equação:

$V P L a=V P L * \frac{(1+i)^{n} * i}{(1+i)^{n}-i}$

em que:

$V P L=$ valor presente líquido.

$i=$ taxa de desconto.

$n=$ duração do projeto, em anos.

\section{Taxa Interna de Retorno (TIR)}

A TIR é a taxa de desconto que iguala o VPL a zero, ou seja, iguala o valor presente das receitas ao valor presente dos custos do projeto. Comparou-se a TIR à taxa mínima de atratividade, e o projeto só seria viável caso a TIR tivesse um valor maior que a taxa mínima de atratividade (REZENDE; OLIVEIRA, 2013). A TIR foi calculada conforme a seguinte equação:

$\sum_{j=0}^{n} R_{j}(1+T I R)^{-j}-\sum_{j=0}^{n} C_{j}(1+T I R)^{-j}=0$

em que:

$T I R=$ taxa interna de retorno $\mathrm{e}(\mathrm{t}=1, \ldots, \mathrm{n})$. 
$R_{j}=$ receita líquida ao final do ano $\mathrm{j}$.

$C_{j}=$ custo no final do ano $\mathrm{j}$.

$j=$ período em que a receita ou o custo ocorrem.

$n=$ duração do projeto, em anos.

\section{Índice Benefício/Custo (IBC)}

O índice benefício/custo mostra as expectativas de ganho por unidade de capital investido. Trata-se de uma estimativa da rentabilidade total do projeto (RASOTO et al., 2012). Basicamente ele divide o VP pelo investimento realizado. Sendo assim, o projeto só será economicamente viável quando o valor do IBC for superior a 1 . Valores inferiores a 1 indicam que o projeto não cobrirá os custos do capital, deste modo deve-se rejeitar o projeto. O IBC foi obtido pela Equação 4.

$$
I B C=\frac{\sum_{j=1}^{n} \frac{B_{j}}{(1+T M A)^{j}}}{F C o+\sum_{j=1}^{n} \frac{C_{j}}{(1+T M A)^{j}}}
$$

em que:

$I B C=$ índice benefício/custo.

$B_{j}=$ valor presente à taxa i da sequência de benefícios.

$C_{j}=$ valor presente à taxa $\mathrm{i}$ da sucessão de custos.

\section{Retorno Adicional sobre o Investimento (Roia)}

O Roia mostra a rentabilidade adicional para um projeto de investimento. Com a taxa mínima de atratividade do mercado já definida, o Roia faz uma análise da porcentagem a mais que o projeto trará de retorno ao produtor/investidor. Desta forma, esse retorno é o análogo percentual do conceito de EVA, que é o que os economistas chamam de custo de oportunidade, significa que um empreendimento tem que produzir um retorno mínimo sobre o capital investido. $\mathrm{O}$ Roia foi obtido pela Equação 5.

$R O I A=\sqrt[n]{(I B C-1)}$

em que:

$R O I A=$ retorno adicional sobre o investimento.

$I B C=$ índice benefício/custo.

$n=$ duração do projeto em anos. 


\section{Payback descontado}

O payback descontado mostra o tempo necessário para que os benefícios do projeto restituam o valor investido (RASOTO et al., 2012). Em outras palavras, expressa o período necessário para que as entradas de caixa se igualem ao que foi inicialmente investido, podendo ser considerado como uma medida de risco do projeto. O payback descontado foi obtido pela seguinte inequação:

$P B E=k$, tal que $\sum_{i=0}^{k} \frac{F_{i}}{(1+j)^{i}}\left(\geq 0\right.$ e $\sum_{i=0}^{k-1} \frac{F_{i}}{(1+j)^{i}}<0$

em que:

$k=$ total de períodos do projeto.

$F_{i}=$ fluxo de caixa no ano.

$J=$ taxa de juros considerados no projeto.

$I=$ número de períodos.

\section{Resultados e Discussão}

\section{Viabilidade do Investimento}

O custo inicial do investimento no Ano 0 (2008) foi de R\$ 190.447,00. Nesse valor foram incluídos todos os custos para a construção do viveiro, o preparo das mudas, a aquisição do trator e implementos agrícolas, a instalação do sistema de irrigação e para a construção de benfeitorias na área de plantio. O fluxo de caixa para a área de 16 ha foi realizado com valores reais ao longo de todo o investimento (Tabela 1).

Concernente às saídas de caixa, o custo de implantação do açaizeiro no $1^{\circ}$ ano (2009) foi de $\mathrm{R} \$ 83.348,80$, e o custo de produção no $2^{\circ}$ ano foi de $\mathrm{R} \$ 62.448,92$. A partir do $3^{\circ}$ ano, os custos apresentaram valores que variaram de $\mathrm{R} \$ 65.953,50$ a $\mathrm{R} \$ 105.068,59$. Assim, para cada hectare, os valores foram de $\mathrm{R} \$ 4.122,09$ a $\mathrm{R} \$ 6.566,78$. O custo de produção médio, resultante do somatório das despesas anuais, dividido pelo período de atividade (20 anos), foi de $\mathrm{R} \$ 100.678,01$ para 16 ha ou R\$6.292,37 por hectare.

Ao considerarmos as entradas de caixa, representadas pelas vendas do fruto, tem-se que o VPL acumulado para a produção de açaí no município de Igarapé-Açu, PA, foi positivo (R\$ 983.394,31) em um horizonte de avaliação de 20 anos.

A TIR da ordem de $20 \%$ ao ano para o plantio de açaizeiro irrigado cobriu os custos de oportunidade, ou taxa de juros proposta pelo FNO para o investimento, que varia de 7,65\% a 12,35\%. A TIR é entre 62\% e 161\% superior às taxas propostas pelo Banco da Amazônia, indicando assim matematicamente a viabilidade econômica do empreendimento. 


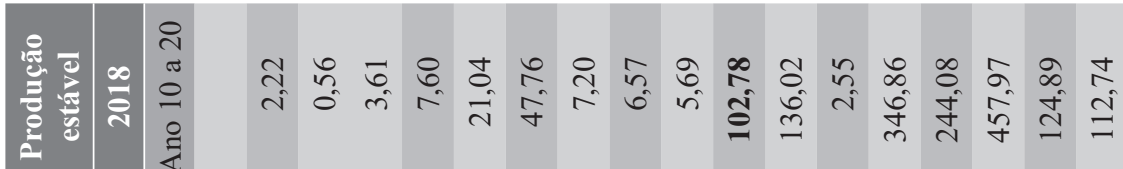

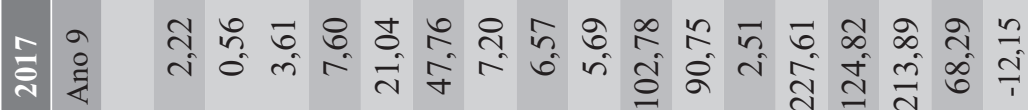

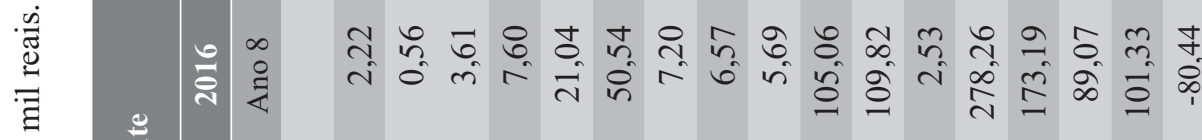

ฮี

㝘

ণิ

$\frac{0}{0}$

艺

n $ก$ ก

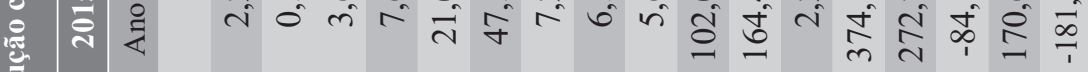

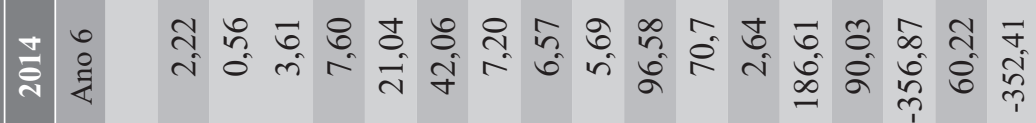

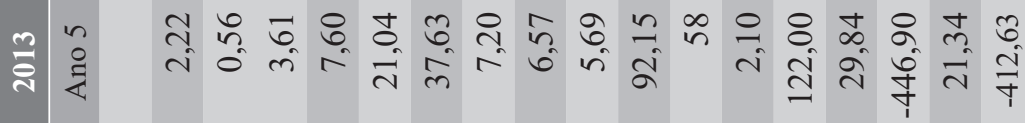

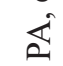

迎

芯

ำ

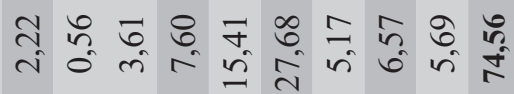

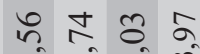

of

웅

은

$m$

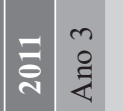

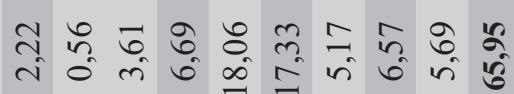

nू

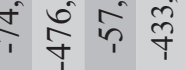

离

을

음

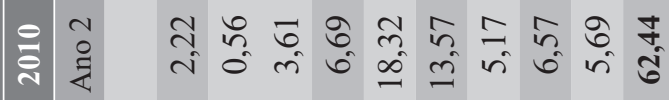

Ұ

กิ

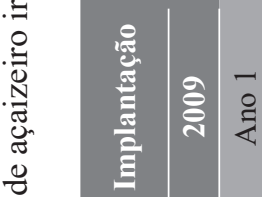

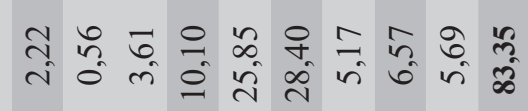

m

๙ิ

ฮี

6

o

బิ్తి

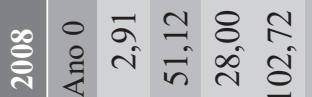

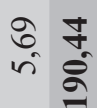

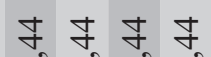

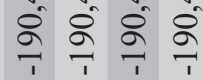

हृ

䒕

ชัฮู

음

肴

$\frac{\sqrt{2}}{\frac{\pi}{8}}$ 
Pode-se considerar, contudo, que a TIR apresenta uma rentabilidade limítrofe entre a viabilidade e a inviabilidade do investimento, sendo um indicador econômico que deve ser analisado junto ao VPL para promover maior confiabilidade e visibilidade do retorno do capital investido. Desse modo, pode-se dizer que, para as condições preestabelecidas, há um ganho real de 13,07\% quando descontada a taxa anual de juros $(6,93 \%)$ empregada no cálculo do VPL, evidenciando a viabilidade do investimento.

Para analisar possíveis variações que podem influenciar na decisão de execução do projeto e melhor observar o risco incorrido foi desenvolvido o espectro de viabilidade de decisão, representado pela Figura 1. Pode-se observar que a amplitude do intervalo de risco é considerada grande, o que torna o projeto atrativo do ponto de vista econômico, pois dificilmente a variação da TMA irá ultrapassar a TIR, o que significa um investimento com boa margem de segurança.

Figura 1. Espectro de viabilidade da decisão do projeto: VPL x TMA.

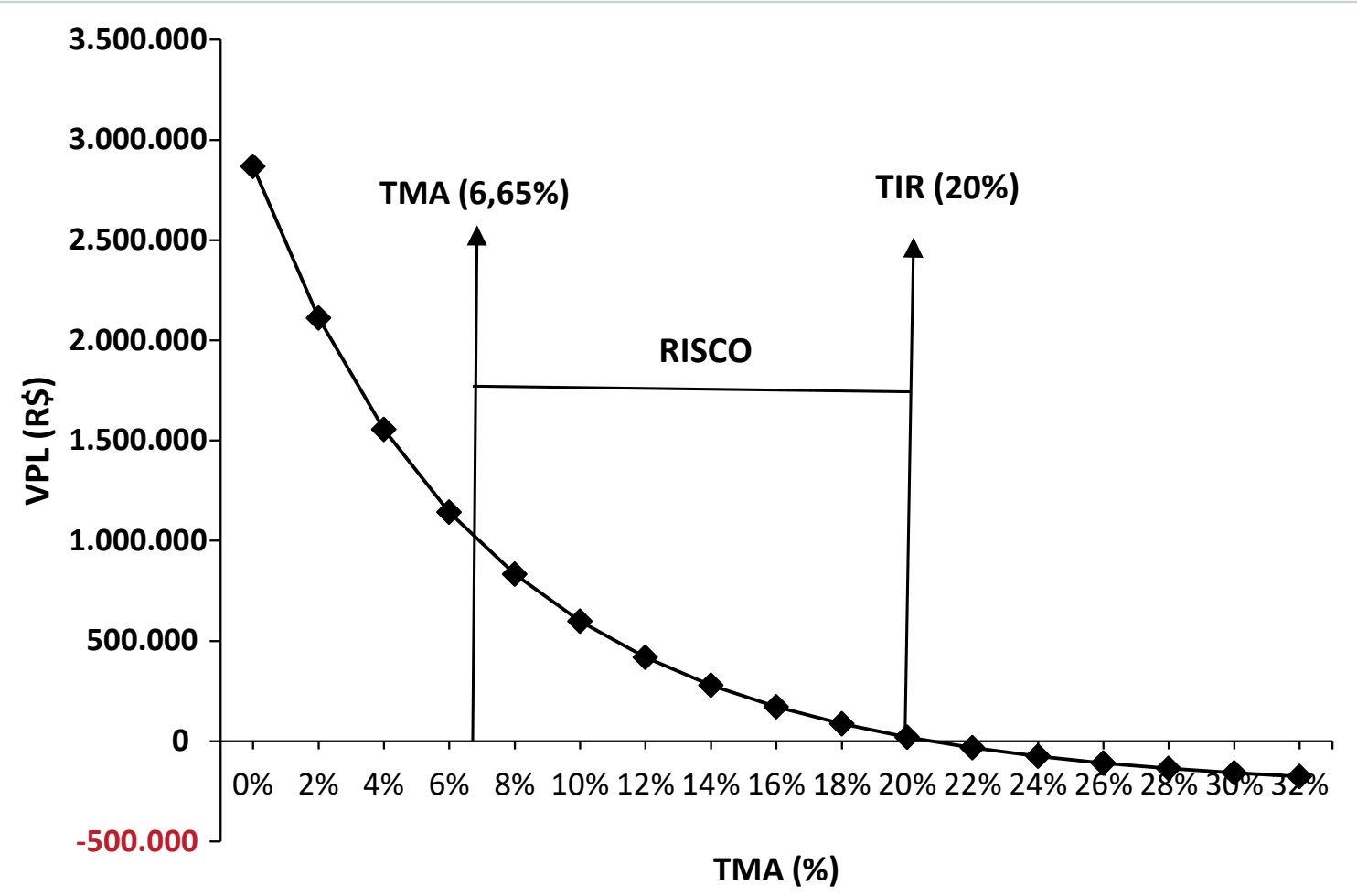

Fonte: Elaborado pelos autores (2018).

O rendimento anual (VPLa), durante a vida útil do projeto, foi de $\mathrm{R} \$ 68.149,22$, descontado a uma taxa anual de 6,93\% (Tabela 2). Quanto ao IBC, o projeto retorna R\$ 6,19, evidenciando a viabilidade do investimento. O IBC a R \$ 6,19 também pode ser interpretado como uma rentabilidade de $519 \%$ em 20 anos.

O plantio dos 16 ha de açaizeiro irrigado teria um retorno adicional sobre o investimento (Roia) de 10\% ao ano, caso o capital tivesse sido aplicado no mercado financeiro a uma TMA de $6,93 \%$ ao ano. Essa medida de desempenho deixa evidente a rentabilidade do plantio dos 16 ha de açaizeiro irrigado. 
Tabela 2. Indicadores de rentabilidade para 16 ha de açaizeiro irrigado no município de Igarapé-Açu, PA, 2018.

$\begin{array}{cc}\text { Indicador } & \text { Valores } \\ \text { VPL } & \mathrm{R} \$ 983.394,31 \\ \text { VPLa } & \mathrm{R} \$ 68.149,22 \\ \text { IBC } & 6,19 \\ \text { ROIA } & 10 \% \\ \text { TIR } & 20 \% \\ \text { Payback descontado } & 9 \text { anos, } 1 \text { mês e } 18 \text { dias }\end{array}$

Fonte: Dados de Pesquisa.

O payback descontado, calculado para o projeto, aplicado a uma TMA de 6,93\% ao ano foi igual a 9 anos, 1 mês e 18 dias, período necessário para a recuperação do investimento inicial. Ou seja, somente a partir desse período o produtor começa, de fato, a obter um lucro na atividade, considerando os custos iniciais de implantação e manutenção do plantio e o custo do capital até aquele período.

Conforme Kreuz et al. (2008), o payback também pode ser utilizado como indicador de risco, dividindo seu valor pelo período do projeto em anos. Esse indicador é quantificado em escala de 0 a 1, valores semelhantes a 0 indicam que não há risco para o investimento, enquanto o valor máximo de 1 corresponde ao risco máximo de aplicação do capital. Considerando um retorno provável de 8 anos e 2 meses no período de 20 anos, obteve-se um indicador de 0,41 , sugerindo um risco médio de não recuperação do capital investido.

Ou seja, no caso do plantio de açaizeiro irrigado em terra firme, depois que o produtor decidir implantar a sua lavoura, fica mais difícil de desistir da atividade no curto prazo, visto que a cultura demorou quase metade do período para cobrir os gastos iniciais. Isso se deve ao fato de o açaizeiro necessitar de alguns anos para iniciar a produção e então estabilizar.

Esse retorno financeiro tardio pode ser considerado como um dos fatores limitantes ao investimento em cultivos em terra firme. Uma alternativa para o produtor reduzir o tempo de retorno do capital seria realizar o plantio consorciado ou associado com culturas anuais, semiperenes ou perenes, que irão propiciar renda nos primeiros anos, além de benefícios nos tratos culturais aplicados às culturas. $\mathrm{O}$ cultivo da bananeira tem sido bastante utilizado pelos produtores de açaizeiros irrigados.

Considerando a média da produção do período, o plantio teve uma safra anual de $64,53 \%$ concentrada no segundo semestre. Na produção verifica-se a formação de dois picos, um no primeiro semestre (janeiro) e dois no segundo semestre (julho e dezembro) (Figura 2). De acordo com Farias Neto et al. (2011), a prática da irrigação e adubação permite melhor distribuição da safra durante o ano, contribuindo para a eliminação/minimização da entressafra. Porém estudos relacionados à quantidade de água e adubação precisam ser aprofundados para que se possa obter maior uniformidade da safra. 
Figura 2. Produção mensal, em porcentagem, no município de Igarapé-Açu, PA, para o período de 4 anos.

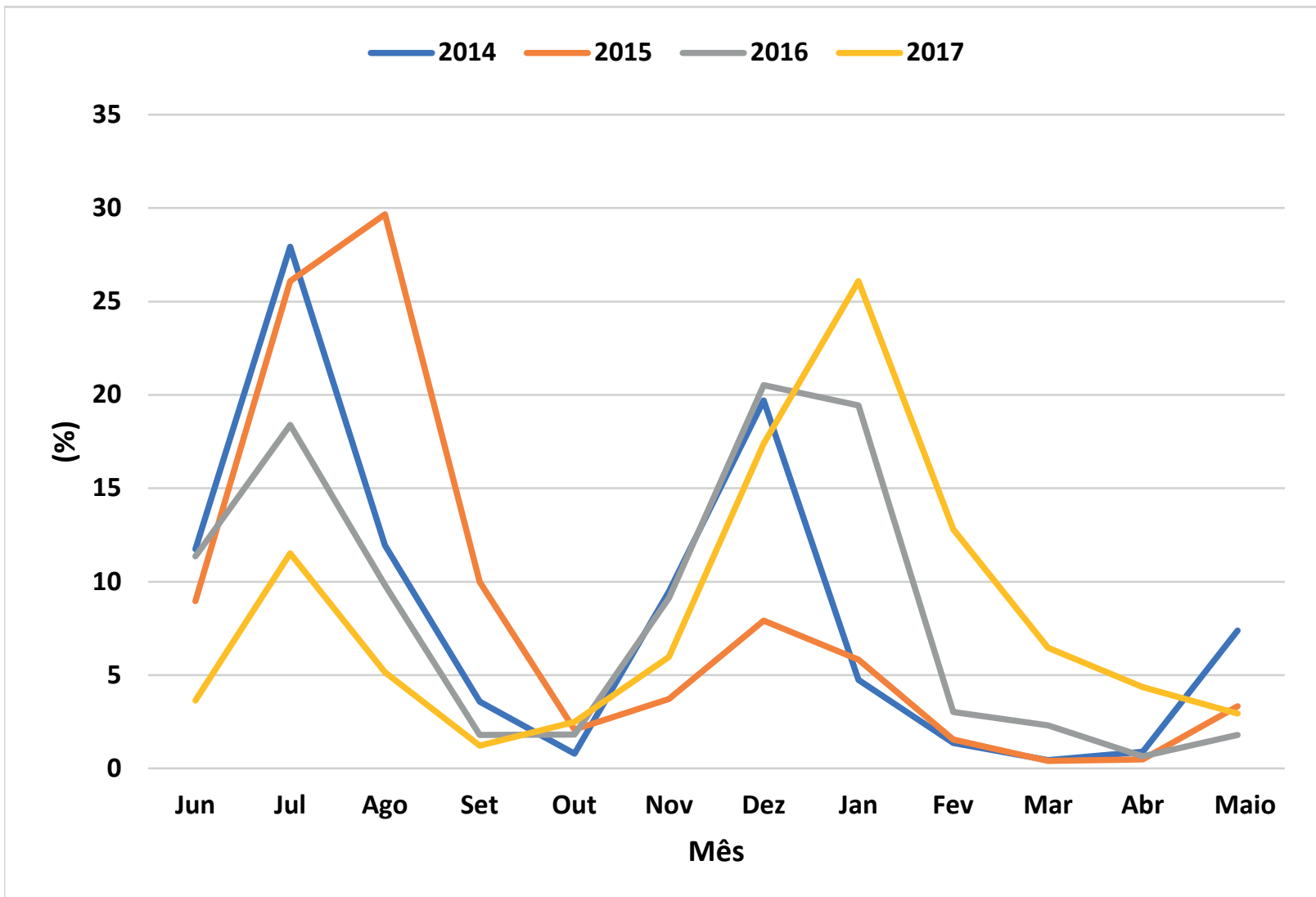

Fonte: Dados da Pesquisa (2018)

\section{Análise de Sensibilidade}

Segundo Mattos (1989), com o passar dos anos, os pesquisadores foram verificando que as famosas "curvas de probabilidade" não eram assim tão indispensáveis, e o risco poderia ser analisado a contento, bastando que se fornecesse a faixa de variação associada a cada elemento do fluxo, bem como de seus prazos.

No caso da plantação de açaizeiro irrigado, a receita durante os anos de 2016 e 2017 sofreu grande impacto pelo decréscimo na produção, decorrente do intenso veranico que ocorreu durante o ano de 2015, com 112 dias sem chuva na área. Nessa concepção, o julgamento do proprietário e de dois especialistas consultados, com relação aos riscos na plantação de açaizeiro irrigado, está associado com a redução da safra devido a veranico, que pode reduzir a produção em até $35 \%$, afetando o lucro líquido na mesma proporção (Tabelas 3 e 4 e Figura 2).

O risco decorrente da queda de preço não representa uma ameaça para o empreendimento, pois o mercado está em franca expansão. Outro risco futuro, ainda não manifestado, está relacionado com o ataque da broca, devido ao monocultivo e à presença de grandes plantios de dendezeiro nas proximidades. 


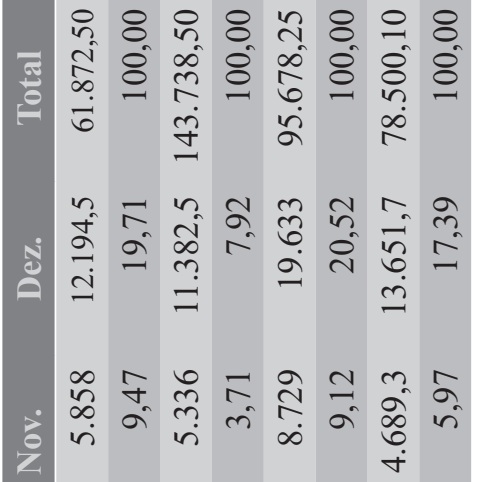

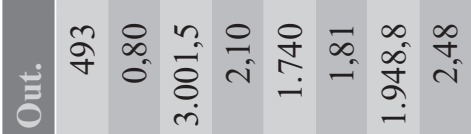

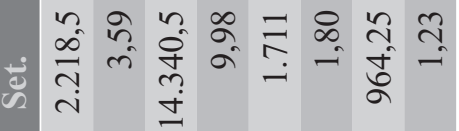

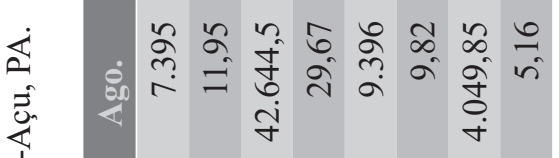

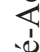

营

o

을

兽

$\stackrel{\circ}{g}$

莡

:

을

ల్ల్ల్

o

듬

$\frac{\pi}{6}$

हี

敢

ํㅡㄹ

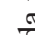

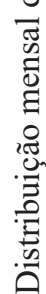

$\dot{m}$

$\frac{\pi}{\frac{\pi}{4}}$

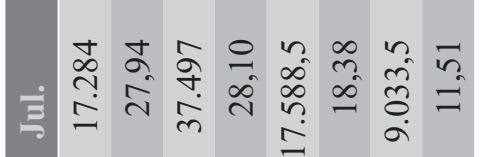

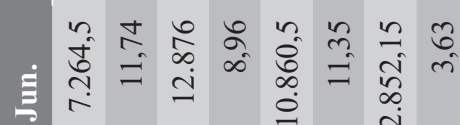

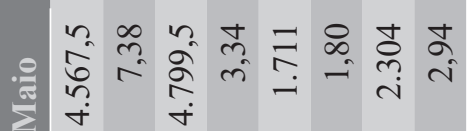

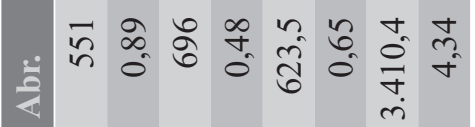

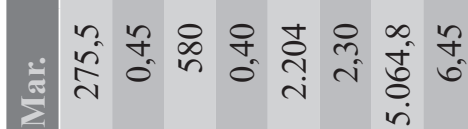

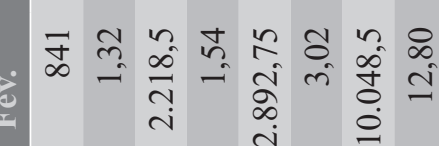

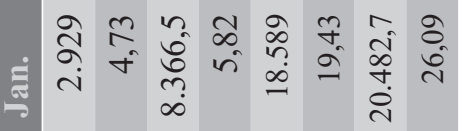

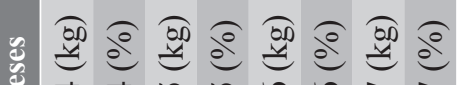

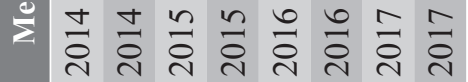

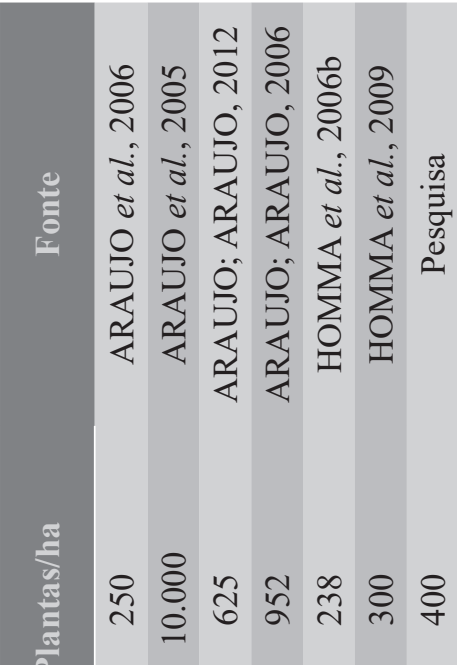

nิ

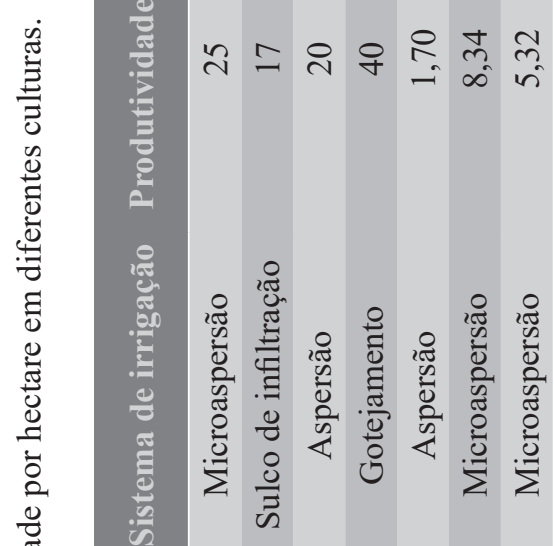

ह

눈ำ

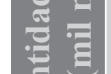

尝

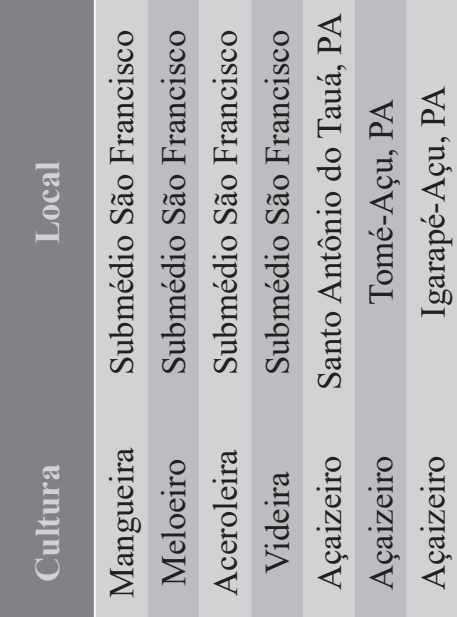




\section{Conclusão}

As análises econômicas realizadas demonstraram que o cultivo de açaizeiro irrigado no município de Igarapé-Açu apresentou retorno econômico, gerando um emprego durante o ano para cada 7 ha cultivados quando estabilizado. Uma alternativa de renda, portanto, para produtores rurais da região, mesmo com um alto investimento na aquisição do sistema de irrigação.

A atividade de açaizeiro irrigado por microaspersão é viável para uma TMA de $6,93 \%$ ao ano, com rendimento líquido de $\mathrm{R} \$ 3.860,40 /$ ha e ganho real de $13,07 \%$, descontada a taxa real de juros empregada no cálculo do VPL.

A TIR, da ordem de $20 \%$ ao ano para o plantio de açaizeiro irrigado, cobriu os custos de oportunidade, ou taxa de juros proposta pelo FNO para o investimento, a qual varia de 7,65\% a $12,35 \%$. A TIR é entre $62 \%$ e $161 \%$ superior às taxas propostas pelo Banco da Amazônia, indicando assim matematicamente a viabilidade econômica do empreendimento.

A produtividade média do açaizeiro irrigado, considerando os 5 anos da safra, foi de 5.326 $\mathrm{kg} / \mathrm{ha}$ e para os 3 últimos anos foi de $6.620 \mathrm{~kg} / \mathrm{ha}$. Essas produtividades são baixas considerando os investimentos realizados. A produtividade do açaizeiro irrigado ficou muito aquém quando comparada com áreas manejadas na várzea, com $6.110 \mathrm{~kg} / \mathrm{ha}$ e $8.400 \mathrm{~kg} / \mathrm{ha}$ para sistema recomendado pela pesquisa agropecuária. A reduzida precipitação pluviométrica verificada nos anos de 2015 e 2016 refletiram na queda da produtividade.

O consumo de água para a irrigação nos 5 meses é da ordem de $6.288 \mathrm{~m}^{3} / \mathrm{ha} / \mathrm{ano}$, sendo considerada baixa quando comparada com o cultivo da mangueira irrigada no Nordeste do País, que atinge $16.000 \mathrm{~m}^{3} / \mathrm{ha} / \mathrm{ano}$. Os preços de venda do fruto de açaí variaram do mínimo de $\mathrm{R} \$ 2,07$ a $\mathrm{R} \$ 2,64 / \mathrm{kg}$. Como o próprio comprador efetua a colheita, nesse valor está embutido o custo de mão de obra.

O estudo apresenta VPL positivo e TIR superior à taxa mínima de atratividade, fixada em $6,65 \%$. Portanto, o projeto é capaz de pagar o investimento inicial e garantir a remuneração mínima exigida pelo investidor. Pelo valor do payback descontado verificou-se que o tempo de retorno do capital inicial investido é inferior ao período do projeto, indicando um baixo risco do investimento. De acordo com os indicadores econômicos VPL, IBC, Roia, TIR e payback descontado, o cultivo de açaizeiro irrigado é viável.

Conforme os valores do payback descontado, verificou-se que o tempo de retorno do capital se dá a partir do $9^{\circ}$ ano. A principal dificuldade está na demora da produção do açaizeiro, que ocorre somente no $5^{\circ}$ ano de plantio, o que torna importante a atenção por parte do investidor, no sentido de verificar se o tempo para essa recuperação está compatível com suas necessidades e disponibilidades financeiras.

\section{Agradecimentos}

Ao engenheiro-agrônomo Antônio Sérgio Coutinho Vicente, da Amazônia Irrigação, pelo fornecimento de informações; a Dra. Nilza Araújo Pacheco, do Laboratório de Agrometeorologia 
da Embrapa Amazônia Oriental, pelo fornecimento dos dados climatológicos de Igarapé-Açu; e ao Dr. José Antônio Leite de Queiroz, pelas observações sobre os riscos do açaizeiro irrigado.

\section{Referências}

ALVES JÚNIOR, J. et al. Respostas do pequizeiro à irrigação e adubação orgânica. Global Science and Technology, Rio Verde, v. 8, n. 1, p. 47-60, 2015.

ARAÚJO, E. P.; ARAÚJO, J. L. P. Análise do custo de produção e rentabilidade do cultivo da uva fina de mesa produzida na região do Submédio São Francisco. In: SIMPÓSIO DE ENGENHARIA DE PRODUÇÃO, 13., 2006, Bauru. Empreendedorismo e sustentabilidade nos sistemas produtivos: anais. Bauru: UNESP: Faculdade de Engenharia, 2006.

ARAÚJO, J. L. P.; ARAÚJO, E. P. Análise da composição dos custos de produção e da rentabilidade econômica do sistema típico de produção da acerola explorada na região do Vale do Submédio São Francisco. In: CONGRESSO BRASILEIRO DE FRUTICULTURA, 22., 2012, Bento Gonçalves. Anais... Bento Gonçalves: SBF, 2012.

ARAÚJO, J. L. P.; ARAÚJO, E. P.; BRITO, W. S. F. Análise do custo de produção e rentabilidade da manga explorada na Região do Submédio São Francisco. Petrolina: Embrapa Semiárido, 2006.

ARAÚJO, J. L. P.; CORREIA, R. C.; ALELUIA, J. C. N. Custo de produção e rentabilidade do melão do Submédio São Francisco. Petrolina: Embrapa Semiárido, 2005. (Embrapa Semiárido. Comunicado técnico, 121).

BARNES, A. P. et al. The influence of diversification on long-term viability of the agricultural sector. Land Use Policy, v. 49, p. 404-412, 2015.

BARRETO, E. D. L. et al. Análise de viabilidade econômica: um estudo aplicado a estrutura de custo da cultura do açaí no estado do Amazonas. Observatorio de la Economía Latino Americana, n. 161, p. $1-17,2012$.

DIMENSTEIN, L.; FARIAS NETO, J. T. Dados preliminares para a produção de frutos de em açaizeiros sob irrigação em terra firme no Estado do Pará. In: DIMENSTEIN, L.; FARIAS NETO, J. T. Irrigação e fertirrigação em fruteiras. Fortaleza: Instituto Frutal, 2008. p. 139-144.

FALESI, L. A. et al. Evolução e interação entre a produção e o preço das frutas no Estado do Pará. Revista de Ciências Agrárias / Amazonian Journal of Agricultural and Environmental Sciences, v. 53, n. 1, p. $69-77,2010$.

FARIAS NETO, J. T. et al. Seleção simultânea em progênies de açaizeiro irrigado para produção e peso do fruto. Revista Brasileira de Fruticultura, v. 33, n. 2, p. 532-539, jun. 2011.

HOMMA, A. K. O. et al. Açaí: novos desafios e tendências. Amazônia: Ciência e Desenvolvimento, v. 1, n. 2, p. 7-23, 2006a.

HOMMA, A. K. O. et al. Custo operacional de açaizeiro irrigado no Nordeste Paraense. Belém, PA: Embrapa Amazônia Oriental, 2006b. 18 p. (Embrapa Amazônia Oriental. Documentos, 255).

HOMMA, A. K. O. et al. Custo operacional de açaizeiro irrigado com microaspersão no Município de Tomé-Açu. Belém, PA: Embrapa Amazônia Oriental, 2010. 8 p. (Embrapa Amazônia Oriental. Comunicado Técnico, 219). 
INSTITUTO BRASILEITO DE GEOGRAFIA E ESTATÍSTICA - IBGE. Produção agrícola municipal: culturas temporárias e permanentes. Disponível em: https://sidra.ibge.gov.br/pesquisa/pam/tabelas. Acesso em: 20 jan. 2020.

KREUZ, C. L.; SOUZA, A.; CLEMENTE, A. Production costs, expectations of returns and risks of honey agribusiness in the plateau north of Santa Catarina State-Brazil. Custos e @gronegocio on line, Recife, v. 4, n. 1, p. 46-61, 2008.

MATTOS, A. C. M. Análise de sensibilidade. Revista de Administração de Empresas, v. 29, n. 1, p. 85-91, 1989.

NOGUEIRA, A. K. M.; SANTANA, A. C. de. Benefícios socioeconômicos da adoção de novas tecnologias no cultivo do açaí no Estado do Pará. Revista Ceres, Viçosa, v. 63, n. 1, p. 1-7, jan./fev. 2016.

NOGUEIRA, A. K. M. et al. A dinâmica do mercado de açaí fruto no Estado do Para: de 1994 a 2009. Revista Ceres, Viçosa, v. 60, n. 3, p. 324-331, maio/jun. 2013.

PESSOA, J. D. C.; TEIXEIRA, G. H. de A. (Ed.). Tecnologias para inovação nas cadeias euterpe. Brasília, DF: Embrapa, 2012. 343 p.

RASOTO, A. et al. Gestão financeira: enfoque em inovação. Curitiba: Aymará Educação, 2012. p. 144.

REZENDE, J. L. P.; OLIVEIRA, A. D. Análise econômica e social de projetos florestais. 3. ed. Viçosa, MG: UFV, 2013. v. 1, p. 386.

ROCHA, S. M. B. M. de. Benefícios funcionais do açaí na prevenção de doenças cardiovasculares. Journal of Amazon Health Science, v. 1, n. 1, p. 1-10, 2015.

RODRIGUES, E. C. N.; RIBEIRO, S. da C.; SILVA, F. L. da. Influência da cadeia produtiva do açaí (Euterpe oleracea Mart.) na geração de renda e fortalecimento de unidades familiares de produção, Tomé Açu-PA. Obeservatorio de la economía Latinoamericana, n. 210, 2015 b.

RODRIGUES, P. L. et al. Atividades desenvolvidas pelas famílias no extrativismo do açaí (Euterpe oleracea Mart.) em Ponta de Pedras-PA. Fortaleza: CONTECC, 2015a. p. 4.

SILVA, P. V. R. da. et al. Consumo hídrico e viabilidade econômica da cultura do feijão caupi cultivado em clima semiárido. Irriga, v. 21, n. 4, p. 662-672, 2016.

SOUZA, A.; CLEMENTE, A. Decisões financeiras e análise de investimentos: fundamentos, técnicas e aplicações. 5. ed. São Paulo: Atlas, 2004.

SOUZA, R. O. R. de M. et al. Cenário da agricultura irrigada no Estado do Pará. Irriga, v. 17, n. 2, p. 177-188, 2012.

TAVARES, G. dos S.; HOMMA, A. K. O. Comercialização do açaí no Estado do Pará: alguns comentários. Revista Observatorio de la Economia Latino Americana, n. 211, 2015. Disponível em: https:// ainfo.cnpitia.embrapa.br/digital/bitstream/item/135458/1/acai-para.pdf. Acesso em: 19 jan.2020.

YAMAGUCHI, K. K. de L. et al. Amazon acai: chemistry and biological activities: a review. Food Chemistry, v. 179, p. 137-151, 2015. 
